\title{
Viewpoint
}

\section{Rheumatology beyond 2000: Wither or whither?}

\author{
W WATSON BUCHANAN* AND PETER M BROOKS
}

From the Florance and Cope Professorial Department of Rheumatology, University of Sydney, The Royal North Shore Hospital, St Leonards, 2065, New South Wales, Australia

\author{
Still thou art blest, compar'd wi' me \\ The present only toucheth thee: \\ But och! I backward cast my e'e, \\ On prospects drear! \\ An' forward, tho' I canna see, \\ I guess an', fear! \\ ROBERT BURNS (1759-1796) 'To a mouse'
}

Many of the rheumatology societies in the Western World have now celebrated their first half-century anniversary and have rightly congratulated themselves on their achievements. Achievements there certainly have been-the unravelling of the pathways of purine biochemistry with control of gouty arthritis, the applications of advances in immunology to the diagnosis and management of connective tissue diseases, the treatment of septic arthritis and prevention of recurrent attacks of rheumatic fever with antibiotic therapy, and the replacement of severely damaged joints by artificial prostheses. ${ }^{12}$ In addition, much basic information has been gathered on the biochemistry of connective tissues, the mechanics of joint lubrication and movement, the pharmacology of inflammation, the genetics of the HLA system, and the modes of action of antirheumatic drugs. Simultaneously and equally with these advances there has been an increase in membership of rheumatology societies world wide, associated with increasing numbers of abstracts and papers submitted to the ever burgeoning number of international meetings and journals. ${ }^{3-5}$ In his presidential address to the American Rheumatism Association on the occasion of its 50th anniversary $\mathrm{Dr}$ James $\mathbf{R}$ Klinenberg felt confident that advances would continue to be made during the next half century, ${ }^{6}$ and $\mathrm{Dr} \mathrm{H}$ Boström, in introducing a recent symposium on rheumatology in transition in

Accepted for publication 20 October 1988.

Correspondence to Professor Peter M Brooks, Department of Rheumatology, Royal North Shore Hospital, St Leonards, NSW 2065, Australia.

${ }^{*}$ Currently on sabbatical leave from McMaster University, Hamilton, Ontario, Canada.
Sweden, felt even more confident, stating that it is 'likely that during the ' 90 s at the latest we can expect just as spectacular breakthroughs in rheumatology as were, for example, the discoveries of vitamin $B_{12}$ and folic acid in haematology, and insulin in endocrinology'. ${ }^{7}$ As McCarty aptly commented, citing an old Chinese proverb, 'prediction is always difficult, especially when it involves the future'. ${ }^{3}$ A large amount of research continues to be done, ${ }^{35} 5$ but many rheumatologists today feel we are at the end of an era of optimism, as Dollery had suggested was the case for medicine in general a decade ago, ${ }^{9}$ and unlike the Burnsian mouse whose only concern was for the present, 'guess and fear'!

\section{Crisis in academic medicine}

One of the major reasons why so many rheumatologists are less optimistic about the future than Klinenberg $^{6}$ and Boström ${ }^{7}$ is that it has been increasingly difficult to attract young investigators to academic medicine, ${ }^{10}$ so much so that Wyngaarden has provocatively suggested that they be designated 'an endangered species'. ${ }^{11}$ The reasons why there continues to be a fall-off in the number of young doctors seeking research appointments in academic departments of medicine are many and complex. ${ }^{10}$ The most important of these, however, appear to be personal financial sacrifice; family pressures; dependence of medical schools (at least in North America) on funding derived from academic clinical practice $^{12-14}$ and uncertainty of continuous funding even when the research is productive. ${ }^{15}$ There is also the quadruple 'threat' of having to be a good doctor, excellent teacher, productive researcher, and skilful administrator, all at the same time,${ }^{14}$ together with increasing constraints upon clinical freedom in academic practice. ${ }^{16-18}$

Perhaps the most important disincentive for young doctors taking up a career in academic rheumatology is the nature of today's research. Gone are the halcyon days of a quarter of a century 
ago when much of the clinical research was physiological in nature and readily achievable by a single person. ${ }^{313} 14$ Research today is much more complex, requiring more protected time, ${ }^{19}$ and collaboration with colleagues in other disciplines. ${ }^{3}$ It is for these reasons that so much more research in clinical departments of medicine in the United States and elsewhere is now being conducted by PhD graduates. ${ }^{20}$ In his Harveian lecture just over a quarter of a century ago Lord Platt concluded that clinical research had reached a point of diminishing returns: 'squeezing the last drop of blood out of a foregone conclusion'. ${ }^{21}$

A further influence operating against recruitment of young doctors to academic rheumatology is the general trend in society away from science ${ }^{22}$ and the decline in a belief in institutions, ${ }^{23}$ expressed by the media $^{24}$ and many high powered philosophers. ${ }^{25}$ This is supported to some extent by the trend among medical educationalists towards emphasising the humanistic model in medical education. ${ }^{26-28} \mathrm{We}$ have argued elsewhere ${ }^{9}$ that the pendulum has swung too far in medical education towards 'caring' and that the time has come to reinstate science, which we believe is the basis of sound medical practice. ${ }^{29-31}$

With a few notable exceptions, such as McMaster University in Hamilton, Ontario, Canada, ${ }^{32}$ still too much is taught to undergraduates, leaving little time for play or thinking. In addition, too many of our medical schools still insist on the rigid compartmentalisation of preclinical and clinical studies, ${ }^{33}$ inherited from William Cullen in Edinburgh, Scotland, in the eighteenth century. ${ }^{32}$ The time has long since past to prune undergraduate curricula of unnecessary information. Efforts are long overdue to make the science of medicine more exciting and relevant to problems of patients. This is particularly true of the study of rheumatic disease, which lacks the drama and technology of other disciplines such as cardiology and surgery. ${ }^{32}$

Much can be done to stimulate students and young doctors in research by electives, ${ }^{34-36}$ but to be successful they require adequate supervision and advice. $^{36} 37$

\section{Types of research}

Research can be broadly classified into two major groups: (a) creative and (b) non-creative.

CREATIVE RESEARCH

This type of research is driven by curiosity. ${ }^{38-40}$ It is creative as it results in new knowledge that could not necessarily have been predicted. Many discoveries from this approach are made by serendipity, even modern day drug discoveries, ${ }^{41}$ although, of course, 'chance favours the mind that is prepared'. ${ }^{42}$ This type of research requires, in addition to technical? skills, an abundance of imagination, ${ }^{3}$ and often ase not is performed by 'eccentric mavericks messing about, wasting time and money'. ${ }^{43}$ It is mores difficult to persuade governments to finance re- $\Omega$ search of this nature, which must allow the resear cher the freedom to pursue his ideas.

NON-CREATIVE RESEARCH

Directed research is essentially non-creative, often requiring a multidisciplinary team effort. Research of this type is targeted towards a specific goal wheres there is a reasonable certainty of outcome. The most $t_{+}^{\circ}$ successful examples of this type of research are thec manufacture of the atomic bomb and the achieve- $+\vec{v}$ ments of the space programme. In medicine exam-음 ples of this type of research include clinical thera-peutic trials and epidemiological and sociological studies. Such research oriented towards a goal is usually welcomed by governments of all political $\vec{\circ}$ persuasions as it generally provides rapid ando 'useful' market related results. It fails, however, when the end point is unknown; the best exampleo being Richard Nixon's Conquest of Cancer Act of 1971.

\section{Future research in rheumatology}

McKeown argued that 'there is a need for a shift in $\frac{3}{3}$ the balance of effort, from laboratory research to epidemiology, in recognition that improvement in health is likely to come in future, as in the past, from modifications of the conditions which lead to dis-? ease, rather than intervention in the mechanism of $\frac{}{3}$ disease after it has occurred'. ${ }^{44}$ On the other hand,

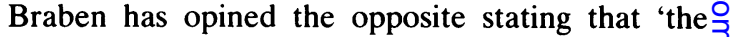
current tendency for national funding organisations to favour research based on extrapolations from $\triangle$ present trends will inevitably have the effect of reducing diversity in national research programmes and possibly the rate at which breakthroughs ${ }_{0}$ occur'. ${ }^{45}$ There is much to be said for both points of $N$ view, but the weakness in McKeown's argument is that it depends on a knowledge of the conditions $\omega$ which lead to the disease. This approach is not applicable to rheumatic disease, the aetiology ofo which is unknown. We therefore believe that emphasis must be placed on basic rather than applied ${ }^{+}$ research if any meaningful advances are to be made. $\frac{T}{0}$ Clinical research, however, is still necessary, ${ }^{119}$ if ${ }_{\mathbb{C}}$ for no other reason than that the clinical researcher? acts as a 'paradigm transducer' between the patient's $\varrho$ disease and the scientist's laboratory. ${ }^{46}$

If young medical graduates are to continue to be 
attracted to academic careers in basic science research it is essential that stable and adequate funding be available and a proper career structure established. ${ }^{47}$ Not only do young scientists need mentors ${ }^{36}$ but also freedom to pursue their ideas. ${ }^{40}$ Although a little uncertainty is often beneficial, too much is a distinct disadvantage in scientific endeavour. ${ }^{47}$ Individuals must be sought who are highly motivated with original and fresh ideas, and lack the wisdom that comes with age and the respect for authority and tradition acquired by didactic pedagogy. Such recruits must be spared the mind crushing effects of current clinical postgraduate training programmes and fellowship examinations, which are designed to produce good doctors but not necessarily scientists with novel ideas.

The problems specifically applying to recruitment to academic rheumatology in North America relate to the economic advantages of procedure orientated disciplines. There is an urgent need if those disciplines, including rheumatology, are to flourish to reduce the currently inflated fees for procedural services and to redistribute the funds to nonprocedure orientated specialties. ${ }^{48}$ The time perhaps has also come to reward cognitive skills. ${ }^{49}$

Training in Australasia and Britain has much to recommend it: the fellowship examination is taken early in the postgraduate training period, and research electives and doctoral theses are encouraged and recognised for final qualification. This is unlike the situation in North America where the postgraduate trainee is more often then not burdened with excessive clinical duties and has to sit an 'exit' examination at the end of his training to obtain his fellowship or boards. This leaves little opportunity for developing a research base.

Above all, such recruits to research must be freed from the stifling effect of traditional funding, which places innovativeness at a disadvantage. Peer review has been aptly described as 'the informed prejudices of wise men', and tends to cause a regression towards the mean, especially at the high end of the spectrum of significance where experiments may appear to be 'too bold'.$^{50-53}$ A totally new paradigm for medical research in rheumatology is required, and for that matter for medical research in general.

\section{Change in the nature of research}

Research in the 1960 s was described by McCarty as often being a 'one man show', ${ }^{3}$ Research today has become very much more complex, often requiring a great deal of sophisticated know-how and multidisciplinary collaboration. In addition, as Booth has commented, clinical medicine and basic science have developed in two quite different directions. ${ }^{54}$
Clinical medicine has undergone centrifugal fragmentation with organ system orientation, whereas basic science has undergone centrifugal consolidation in terms of molecular biology. ${ }^{54}$ We now exist in a scientific era reminiscent of Rainer Maria Rilke's 'two solitudes', with clinical researchers unable to exploit the new advances in molecular biology and basic scientists unable to define the clinical problems which need to be solved ${ }^{55}$ Clearly we need not only programmes to train clinical investigators but also centres where young investigators can learn the new developments of science, particularly molecular biology. National research centres have been developed with varying success, ranging from only partial success in the case of Northwick Park in the United Kingdom ${ }^{54}$ to extreme success in the case of the National Institutes of Health in the United States. ${ }^{40}$ Hollenberg and Siminovich have strongly made a case for such a centre in Canada, believing 'it is impossible to conceive of a university sector mounting any effective response'. ${ }^{56}$ We agree that such a national centre, especially along the lines of the NIH, is admirable, but would be concerned if this were at the expense of the university sector. Variety is, we believe, important in research, and there is much sense in McMichael's comments that 'science, like education, can never be standardised into any pattern as the underlying ideas to be transmitted are in a process of continuous change'. ${ }^{57}$ The current development of 'centres of excellence' in universities needs to be monitored carefully as it is important that units not so designated do not become 'centres of non-excellence' by default. The centre of excellence, however, can provide a focus for the whole institution and act as a stimulus for other units. Unfortunately, the decision to have a national centre for research or centres of excellence in universities, or both, will largely, if not entirely, be decided by political rather than scientific considerations.

Medical research needs to be stimulated at all levels whether in primary care or in the molecular biological laboratory. It is essential that young persons at the start of their medical career are embued with this ethos. Research, we believe, is primarily an attitude of mind; beginning with curiosity and questioning, then planning and executing an experiment, and, finally, drawing valid conclusions. It is essential that this attitude be developed early in the undergraduate course and continued for the whole of professional life. Health care in every nation is beginning to pose an intolerable burden on the public purse. Governments must realise that if escalating health care costs are to be controlled money must be directed into basic research and into the areas of prevention and 
evaluation of health care technology. Control of the health care dollar will only come from a healthy association of academic medicine with all aspects of health care delivery and a stimulation of the questioning ethos across the whole spectrum of medical care providers. These considerations pertain equally to the microcosm of rheumatic diseases and to the macrocosm of medicine in general.

\section{References}

1 Weissmann G. The introduction is over. Arthritis Rheum 1983; 26: 1297-302.

2 McCarty D J, ed. Landmark advances in rheumatology. Palo Alto, California: Contact Associates International Ltd, 1985.

3 McCarty D J. American rheumatology-the future of our guild: antidisestablishmentarianism. Arthritis Rheum 1980; 23: 969 76.

4 Bole G G. The American Rheumatism Association, 1990. Arthritis Rheum 1982; 25: 1-9.

5 Bennett J C. American rheumatology: markings. Arthritis Rheum 1983; 26: 548-52.

6 Klinenberg J R. 1984-2034: the next half-century for American rheumatology. Arthritis Rheum 1985; 28: 1-7.

7 Boström $\mathrm{H}$. Introduction to symposium on rheumatology in transition. Scand J Rheumatol 1987; 64 (suppl): 5.

8 Dollery C. The end of an age of optimism. London: Nuffield Provincial Hospitals Trust, 1978: 33-53. (Rock Carling Fellowship.)

9 Brooks P M, Buchanan W W. The flight from medical academe. Med $J$ Aust 1988; 148: 426-7.

10 Wyngaarden $\mathrm{J}$ B. The clinical investigator as an endangered species. $N$ Engl J Med 1979; 301: 1254-9.

11 Jennett B. Stagnation and despair in medical research. Br Med $J$ 1985; 290: 854 .

12 Petersdorf R G. The evolution of departments of medicine. $N$ Engl J Med 1980; 303: 489-96.

13 Fredrickson D S. Biomedical research in the 1880s. N Engl J Med 1981; 304: 509-17.

14 Petersdorf R G. Some perturbations in medicine. JAMA 1982; 248: 2098-101.

15 Borek $\mathrm{E}$. The loneliness of the original investigator. Nature 1976; 264: 100.

16 Burnham J C. American medicine's golden age. What happened to it? Science 1982; 215: 1474-9.

17 Hoffenberg R. Clinical freedom. London: Nuffield Provincial Hospitals Trust, 1987.

18 Winkenwerder W, Ball J R. Transformation of American health care. The role of the medical profession. $N$ Engl J Med 1988; 318: 317-9.

19 Tan E M. A time for change and a time to remain the same. Arthritis Rheum 1985; 28: 1201-4.

20 Fishman A P, Jolly P. PhDs in clinical departments. Physiologist 1981; 24: 17-21.

21 Platt Lord. Medical science: Master or servant? Br Med J 1967; iv: $439-44$.

22 Brunette $\mathbf{M ~ G}$, Monast $\mathbf{M}-\mathbf{A}$. The vanishing clinician scientist. Can Med Assoc J 1982; 127: 675-6.

23 Perky W. Changing patterns in higher education. Proceedings of the Royal Society of Medicine 1977; 70: 679-85.

24 Lawson $H$. The fallacy of scientific objectivity. The Listener 1986; 115: 12-13.

25 Theocharis T, Psimopoulos M. Where science has gone wrong. Nature 1987; 329: 595-8.

26 Jonas $S$. The case for change in medical education in the United States. Lancet 1984; ii: 452-4.
27 Panel on the general professional education of the physiciar and college preparation for medicine. Physicians for the : twenty-first century. The GPEP report. Washington DC, USA Association of American Medical Colleges, 1984.

28 Arnold R M, Povar G J, Howell J D. The humanities humanistic behaviour, and the human physician: a cautionary을 note. Ann Intern Med 1987; 106: 313-8.

29 Campbell E J M. Basic science, science, and medical education Lancet 1976; i: $134-6$.

30 Black D. Cui bono? Br Med J 1977; ii: 1109-14.

31 Balint G P, Buchanan W W. Undergraduate education in rheumatology. Br J Rheumatol 1986; 25: 238-9.

32 Bellamy N, Potter S, Rooney P J, Buchanan W W. L'étude dela rhumatologie à la Faculté de Medécine de McMaster. L $\vec{\omega}$ Revue d'Education Medicale 1986; 9: 26-37.

33 Maddison D C. What's wrong with medical education? Med Educ 1978; 12: 97-102.

34 Ross C A. Basic research by medical students. J R Soc Medbo 1981; 74: 7-10.

35 Burns T W. Manpower needs for academic medicine Intern Med 1982; 97: 611-2.

36 Harris E D. Wanted: catalysts for growth Arthritis Rheum 1986; 29: 1297-300.

37 Wood G M, Catford J C. Research post-MRCP. J R Colt Physicians Lond 1986; 20: 89-94.

38 Judson H F. The eighth day of creation: makers of the revolution in biology. New York: Simon and Schuster, 1980.

39 Thomas L. Late night thoughts on listening to Mahler's ninth symphony. New York: Vicking Press, 1983: 28.

40 Marston R Q. Dilemmas of decision-making. Nature 1987; 329: 683-5.

41 Dunlop D. Medicines in our time. London: Nuffield Provincial Hospitals Trust, 1973.

42 Vallery-Radot R. The life of Pasteur. New York: Garden City 1923: 76. (Translated by $\mathrm{R} L$ Devonshire.)

43 Carvel J. The defiance of science: commentary from Westmins ter. Lancet 1988; i: 600.

44 McKeown T. The role of medicine: Dream, mirage or nemesis? London: Nuffield Provincial Hospitals Trust, 1976: 179. (Rock Carling Fellowship.)

45 Braben D W. Innovation and academic research. Nature 1985 316: $401-2$.

46 Jerry L M. Paradigm shifts in clinical research: the tomato effect revisited. Clin Invest Med 1985; 8: 249-50.

47 Solomon S, Lawley A. Medical research in Canada-a history of accomplishment, a future of uncertainty. Annals of the Royat. College of Physicians and Surgeons, Canada 1986; 19: 119-22.

48 McCarty C J. Why are today's medical students choosing high- 3 technology specialities over internal medicine? $N$ Engl J Med 1987; 317: 567-9.

49 Kelly W N. A new role for the ARA in guiding our destiny. D Arthritis Rheum 1987; 30: 1201-4.

50 Irvine J, Martin B, Peacock T, Turner R. Charting the decline in British science. Nature 1985; 316: 587-90.

51 Lock S. A difficult balance: editorial peer review in medicine. London: Nuffield Provincial Hospitals Trust, 1985.

52 Smith D C, Collins P M D, Hicks D M, Wyatt S. National WN performance in basic research. Nature 1986; 323: 681-4.

53 Martin B R, Irvine J, Narin F, Sterritt C. The continuing decline of British science. Nature 1987; 330: 123-6.

54 Booth C C. The Stoker report and the future of Northwick Park. Lancet 1986; i: 372-4.

55 MacLeod S M. Science and politics: two solitudes. Clin Invest Med 1986; 9: 55-7.

56 Hollenberg $\mathrm{C} \mathrm{H}$, Siminovich $\mathrm{L}$. New ventures to attract new resources. Can Med Assoc J 1986; 135: 1349.

57 McMichael J. Changing patterns in higher education. Proceed- $-\bar{T}$ ings of the Royal College of Medicine 1977; 70: 899-90. 